\title{
Plant Species Diversity and Composition of the Homegardens in Dilla Zuriya Woreda, Gedeo Zone, SNNPRS, Ethiopia
}

\author{
Melese Mengitu ${ }^{1}$, Daniel Fitamo ${ }^{2}$ \\ ${ }^{1}$ School of Plant Science, Haramaya University, Haramaya, Ethiopia \\ ${ }^{2}$ Biology Department, Hawassa University, Hawassa, Ethiopia
}

Email address:

melese43@yahoo.com (M. Mengistu),danielfitamo@gmail.com (D. Fitamo)

\section{To cite this article:}

Melese Mengitu, Daniel Fitamo. Plant Species Diversity and Composition of the Homegardens in Dilla Zuriya Woreda, Gedeo Zone, SNNPRS, Ethiopia. Plant. Vol. 3, No. 6, 2015, pp. 80-86. doi: 10.11648/j.plant.20150306.14

\begin{abstract}
Homegardens are one of the most complex and diverse agroforestry systems worldwide and played an important role towards the development of early agriculture and domestication of crops and fruit trees. The study was conducted with an objective of investigating the role of homegardens for improved livelihoods and food security in Dilla Zuriya Woreda. Simple random sampling was used to obtain a study population of 120 households, to whom an interview schedule and an observation checklist was used. The average size of the homegardens of the study area ranges from $250 \mathrm{~m}^{2}$ (small) to $2000 \mathrm{~m}^{2}$ (large) with mean of $665.42 \mathrm{~m}^{2}$. The Shannon Weaver indices of plant species in Chichu, Golla, Bulla and Shigedo homegarden were $\mathrm{H}^{\prime}=3.52, \mathrm{H}^{\prime}=3.46, \mathrm{H}^{\prime}=3.34$ and $\mathrm{H}^{\prime}=3.37$ respectively. The dominance index also shows that only a few species dominated the homegardens in Bulla $(\lambda=0.056)$ as compared to Chichu $(\lambda=0.048)$, Golla $(\lambda=0.052)$ and Shigedo $(\lambda=0.054)$ homegardens. The evenness index shows that in Chichu homegardens most of the species are equally abundant $(\mathrm{E}=0.45)$. In total, 75 different plant species with trees (44\%), shrubs $(20 \%)$, herbs $(32 \%)$ and climbers $(4 \%)$ were recorded under ten use categories. Of the identified species $40 \%$ were food crops, $17.3 \%$ were crops used for income, $13.3 \%$ were medicinal, $17.3 \%$ were plants used as live fence, $20 \%$ were used for building and fuel, $10.6 \%$ were used for home materials, $4 \%$ were used as spices, $5.3 \%$ were stimulants, $10.6 \%$ were used as ornamentals and $20 \%$ plant species were used for shading. The homegaden in the study area were highly diversified with different plant species that provide multiple use for the household.
\end{abstract}

Keywords: Homegarden, Diversity, Agroforesry

\section{Introduction}

People have had homegardens for thousands of years [1]. They consist of an assemblage of plants and may include trees, shrubs, vines, and herbaceous plants, growing in or adjacent to a homestead or home compound [2]. Homegardens are one of the most complex and diverse agroecosystems worldwide and played an important role towards the development of early agriculture and domestication of crops and fruit trees, a still ongoing process [3]. Homegardens are commonly defined as a piece of land with a definite boundary surrounding a homestead, being cultivated with a diverse mixture of perennial and annual plant species, arranged in a multilayered vertical structure, often in combination with raising livestock, and managed mainly by household members for subsistence production [4].
Homegardening has proven to be an effective approach to improved household food security. The production of vegetables and fruits in the homegarden contributes significantly to increased consumption of these types of foods in many countries in Asia [5]. Homestead production is also an important source of supplementary income for poor rural and urban households around the world [6]. Moreover, crop plants, trees and tree products from homegardens play an important role in the household food security, as it is a sustainable source of food, fruits and vegetables [7].

Extensive areas of traditional agroforestry homegarden exist in the south and southwestern parts of Ethiopia [8]. Most of these gardens are located at altitudes of 1500-2300 m.a.s.l. where moisture and temperature conditions are favorable for agriculture [9]. These gardens are characterized by a unique combination of two native perennial crops: enset and coffee. Enset is an herbaceous multipurpose crop, and a 
staple food for about 10 million people in the region. Coffee (Coffea arabica L.) is mainly used as cash crop, but also for household consumptions [10]. In its agro forest area, Arabica coffee occurs in the multi-strata of forest ecosystems and thus it is a shade-adapted plant. Its response to light has caused it to be traditionally considered a heliophobic plant requiring high, somewhat dense cover in a plantation [11].

The enset-coffee-livestock-tree system of southwestern Ethiopia represents a typical multistory homegarden. The upper storey is dominated by broad-leaved trees (e.g., Cordia, Croton, Millettia) fruit crops (Avocado, Mango), the middle storey containing Ensete ventricosum, Musa paradisiaca, Coffea arabica and Zea may while vegetables, spices and herbs cover the lower canopies [8]. The EnsetCoffee characterized homegardens have been stable agricultural systems for centuries supporting very dense populations of up to 500 persons per square kilometer [9]. Household homegardening has a vast potential for addressing the food, health and income needs of the rural households [12]. The diversified plant and its composition in homegaden plays a great role at a household level to alleviate food insecurity and which in the study area is not yet clearly understood and documented. Therefore, this study is to identify the plant species diversity and composition of the homegardens of the study area

\section{Materials and Methodology}

\subsection{Description of Study Area}

The study was conducted in Dilla Zuriya Woreda, which is one of the six Woredas of the Gedeo Zone, Sothern Nations Nationalities and People's Regional State (SNNPRS), Ethiopia. Dilla Zuriya Woreda has a total area of 12764 hectares and it is geographically located between $5^{\circ} 84^{\prime \prime}-6^{\circ} 43^{\prime \prime}$ North latitude and $38^{\circ} 08^{\prime \prime}-38^{\circ} 44^{\prime \prime}$ East longitude. It is located at $359 \mathrm{~km}$ south of Addis Ababa and $90 \mathrm{~km}$ from capital of the regional state, Hawassa. It is bounded with Sidama zone in the north, Oromiya Regional State in the south and northeast, and Wonago Woreda of the Gedeo Zone in the south.

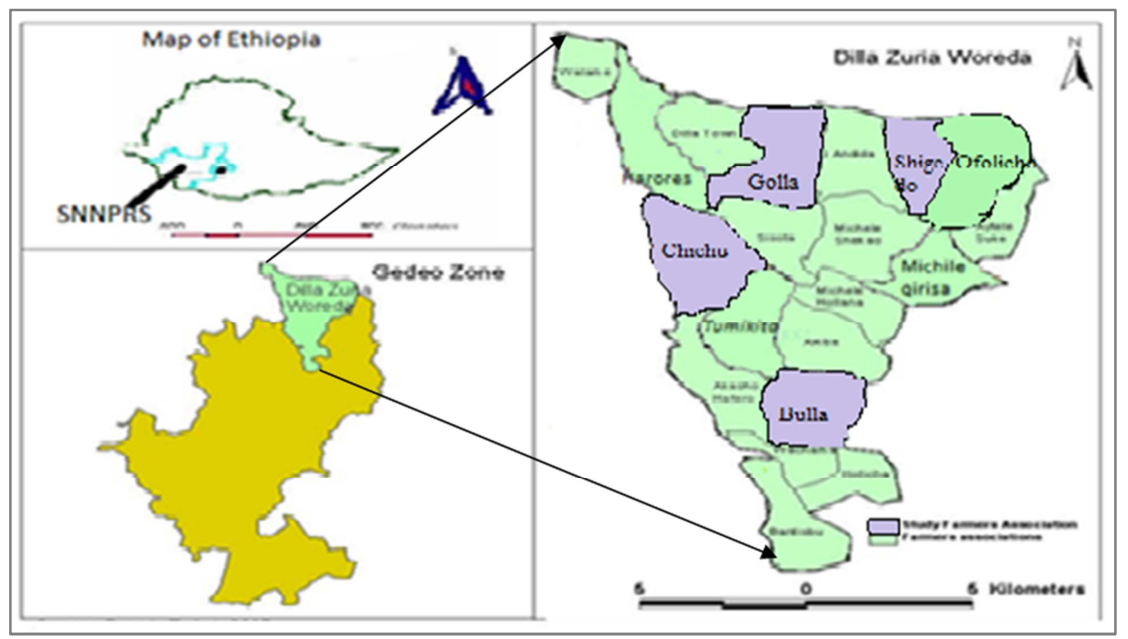

Figure 1. The map of study area. Source: [13].

\section{Climate}

Dilla Zuriya Woreda ranges from 1350 to 2600 m.a.s.1. Regarding the agroclimate zones, the Woreda is predominantly occupied by Woyna Dega (70\%) and Dega and Kola constitutes 23 and $7 \%$ of the total area of the Woreda, in that order. The mean annual temperature of the woreda ranges between $18-27^{\circ} \mathrm{C}$ and the mean annual rainfall ranges between 1400-1800 $\mathrm{mm}$. Thus, the climate of Gedeo zone is characterized as warm humid temperate and it is suitable for abundant forest cover. This Woreda receives the rain for most of the years with an approximately three-month interval (December-March). Because of this, the farmers practice Enset- Coffee based homegardens with intercropping of different perennial and annual crops.

\subsection{Data Collection}

This study was conducted between January and August 2012. From total of 17 Kebeles in the study area, only four
Kebeles (Golla, Chichu, Bulla and Shigedo) were selected purposely. The choice of the Kebeles was based on their proximity to the capital of Gedeo Zone, Dilla, and the type of homegarden practices, in which Enset ventricusom or Coffea arabica crop was dominant. Accordingly, the two Kebeles, Chichu and Golla, are near to the capital of Gedeo Zone, Dilla. They are about 0.5 and 1.5 kilometers away respectively from the capital of zone but Bulla and Shigedo are 13.5 kilometers and 15 kilometers away from the Dilla town. Similarly, the homegarden types of Chichu and Golla are coffee dominated while that of Bulla and Shigedo are enset dominant. For this study three types of homegarden are identified based on their size, small $\left(<500 \mathrm{~m}^{2}\right)$, medium $\left(500-1000 \mathrm{~m}^{2}\right)$ and large $\left(>1000 \mathrm{~m}^{2}\right)$.

\subsubsection{Interview and Survey}

Various tools of data collection methods were followed to gather data. Primary data were collected through structured and semi-structured interviews and direct observation. In the 
structured interview the selected informants were asked to categorically list plant species in their homegarden using their vernacular names that helped to characterize variation in gardening knowledge and production practices among the owners of a homegarden.

These semi-structured interview were conducted on 30 household from each Kebeles or totally 120 informants were selected from the study area randomly. During the survey, all the selected homegardens in the study area were visited and all the useful plant species i.e., plants used for food, medicine, sell, live fence, building or home materials, fuel, shade and ornamental were recorded. Most of the plants encountered in the homegarden of each household had multiple uses but categorizing was done based on the main use that was illustrated by farmers. They referred the main use of plant by the value that plant have in their livelihood system.

The homegarden composition was assessed through field observation. During the observation, plant inventory survey was performed by using a structured format, which included common and botanical names of plants, uses of plants, parts of the plant used for food and habitat of each plant. The survey was carried out with participatory observations and plants identifications with local names.

Voucher specimen of valuable were prepared, processed and dried in the field. These specimens were identified at Ethiopian National Herbarium (ENH), Addis Ababa University/Ethiopia. The experts identified the specimens by comparing with already identified (authentic) specimens or using taxonomic literatures and unpublished manuscripts at $\mathrm{ENH}$.

\subsubsection{Focus Group Discussion}

Group discussions were conducted with four key informants selected from four study Kebeles. These four key informants were selected in each Kebele based on the information obtained from Woreda Agricultural and Rural development Office and Kebele administrations. The key informants are those considered by their community as very knowledgeable about their homegarden management practice and the plant species that they cultivate. These four key informants were selected from each homegarden type (small, medium and large) in these four study Kebeles. The group discussions were conducted for consecutive four days. During the discussions, the key informants were allowed to discuss what types of food crops were found in their homegardens, what are the roles of their homegardens in their daily food supply and the amount of income earned from their homegardens annually. Then the result was compared with that of the selected households. To see the consistency of their discussion with their homegardens plant species, actual visit of each key informant homegarden was made. They were also asked to mention the major factors that hinder the productivity of their homegardens.

\subsection{Data Analysis}

The inventoried plant species are organized accordingly to identify homegarden composition with respect to its use category. The frequency distribution and percentage composition of useful plant species are identified.

The collected data was analyzed by using SPSS (Statistical Package for Social Sciences) version 16 [14]. Descriptive statistics were used to generate frequency distribution and percentages. Shannon-Weiner diversity index (H`or SWI) [15] was calculated using the formula:

$$
\mathrm{H}^{\prime}=-\sum_{i=1}^{S} p i \times \ln p i
$$

Where $\mathrm{H}^{\prime}=$ Shannon index of diversity

$\mathrm{S}=$ Number of species

ln = Natural/Napierian logarithm [A logarithm to the base e] $\mathrm{p}_{i}=$ Abundance of the $i^{\text {th }}$ species [the proportion of species i relative to the total number of species]

The term $p_{i} \ln p_{i}$ is calculated and summed for each species in the community. With this index, diversity increases as species become more evenly distributed in abundance, and more species are added to the community. The maximum value that the SWI can reach depends on the number of species in the community (maximum $\mathrm{H}^{\prime}=\ln \mathrm{S}$ ). Evenness index $\left(E=H^{\prime} / \ln s\right)$ was used to describe the diversity in terms of evenness i.e. how equally abundant the species were in the homegardens. This standardizes evenness on a scale from $0-1$. In addition, Simpson's index, ' $\lambda$ ' was used to describe the dominance i.e. the degree that a community is dominated by one or a few common species.

$$
\lambda=\sum_{i=1}^{S}(p i)^{2}
$$

The index measures dominance on a $0-1$ scale. If only one species is present in the community, $\mathrm{P}_{\mathrm{i}}=\lambda=1$ will be the maximum value.

\section{Results and Discussion}

\subsection{Household Characteristics}

The study revealed that the average age of the respondents was 47.7 with minimum of 31.0 and maximum of 75 . Majority of the respondents (53.3\%) falls between 40 to 60 while $34.2 \%$ and $12.5 \%$ of the respondents were between the ages ranges of $25-40$ and $>60$, in that order. Out of 120 surveyed families, $15 \%$ were female-headed households and the rest were male-headed households. Although 14.2\% of the respondents were uneducated, majority of homegardeners $(85.8 \%)$ had one form of formal education. Regarding the wealth status, $73.3 \%$ are medium, $21.7 \%$ are poor and the remaining $5 \%$ are high with better living condition. The average family size in study Kebeles were 6.76 persons per household with a range stretching between $2-13$. The total land size of each household consists of the farmland and homegarden. Of 120 households, $75 \%$ have farmland ranging between 0.5 - 1 hectare. Age structure and sex composition of a study area are fundamental demographic data when examining household characteristics. The age composition largely influences the agricultural and homegardening activities of a household. At a household level, the sex composition, age structure, education level, family size, and land size have an impact on the availability of labor in 
allocation for different tasks that has great role for the food security or for the earning of income [16].

\subsection{Prominent Features of the Homegardens}

\subsubsection{Homegarden Size}

Homegarden, locally called as "Gattae", is an essential part of the food production system in the study area in supplementing household field production. Three type of homegarden were identified in study Kebeles on the bases of their size.

Table 1. The size of hmegarden in different category.

\begin{tabular}{lll}
\hline Homegarden types & No. of homegardens & Percent \\
\hline Large & 43 & 35.8 \\
Medium & 60 & 50 \\
Small & 17 & 14.2 \\
Total & 120 & 100 \\
\hline
\end{tabular}

Of the surveyed households, all (100\%) are practicing homegarden to grow different types of plants to fulfill various needs of household members. The size of homegardens in the study area ranges between $250 \mathrm{~m}^{2}$ $2000 \mathrm{~m}^{2}$ with an average of $665.42 \mathrm{~m}^{2}$. The average homegarden sizes in the three categories was $314.7 \mathrm{~m}^{2}, 503.3$ $\mathrm{m}^{2}$ and $1046.5 \mathrm{~m}^{2}$ in small, medium and large sized homegardens respectively. Majority (50\%) of the households had medium sized homegardens ranging between $500 \mathrm{~m}^{2}$ to $1000 \mathrm{~m}^{2}$. Common garden size range from about $100 \mathrm{~m}^{2}$ to more that $2000 \mathrm{~m}^{2}$, but in extreme cases, sizes as below $20 \mathrm{~m}^{2}$ and as high as $6000 \mathrm{~m}^{2}$ has been recorded [17].

\subsubsection{Plant Diversity}

In the present study a total of 75 plant species with ten major use categories have been recorded in the studied homegardens out of which $44 \%$ were trees, $14.7 \%$ were shrubs, $38.6 \%$ were herbs and $2.7 \%$ were climbers representing 48 families. The average plant diversity per homegaden was 21 plant species, ranging from 11 to 37 throughout the homegardens. Similarly, in total 120 plant species were recorded in the home garden systems of Sidama [10]. The total number of species encountered in the homegardens in Assam, was 122 [18].

Table 2. Species diversity of the different homegardens of the study area.

\begin{tabular}{lll}
\hline Homegarden type & Family & Species \\
\hline Small & 19 & $33(44 \%)$ \\
Medium & 31 & $57(76 \%)$ \\
Large & 23 & $39(52 \%)$ \\
Over all & 48 & $75(100 \%)$ \\
\hline
\end{tabular}

The result revealed that the species diversity in the small homegarden is $44 \%$ and it is lower than that of medium type $(76 \%)$. The possible reason is that households with small homegarden select to grow the most useful plant species in their homegardens and give less focus with plant of less use. For this reason, their homegarden were dominated by few but most useful plant species. Similarly, households with large homegarden have enough space but use it for other activities, like livestock rearing and resting place. Across the three types of homegardens, 48 plant families were observed. The most common families included, Rutaceae, Asteraceae, Fabaceae, Solanaceae, Poaceae, and Cucurbitaceae. Rutaceae contained the highest number of food plant species (5) with 1 ornamental species, while Ephorbiaceae had the most ornamental species (4) with 1 medicinal species. Fabaceae, Cucurbitaceae, Poaceae and Solanaceae all had mostly equal number of food plant species. Medicinal plants were equally distributed among several families, with 3 species found in Fabaceae. Similarly, [19] reported that tree density was much higher in the Sri Lanka homegardens that mean density of timber and multipurpose trees in the homegardens at the urban fringe was approximately $35 \%$ greater that of settled homegardens in same surrounding.

Table 3. Composition of different plant forms (habits) in the homegardens of the study area.

\begin{tabular}{lllll}
\hline Homegarden type & Tree & Shrub & Herb & Climber \\
\hline Small & 12 & 6 & 13 & 1 \\
Medium & 24 & 10 & 15 & 3 \\
Large & 18 & 7 & 8 & 2 \\
Overall & 33 & 15 & 24 & 3 \\
\hline
\end{tabular}

With respect to the habit of plants, the tree, shrub, herb and climber plant species account $44 \%, 20 \%, 32 \%$ and $4 \%$ respectively. In all the three types of homegarden trees plants dominated followed by herbs and shrubs (Table 4).

Table 4. Diversity, dominance and evenness index of plant species across the different homegardens of the study Kebeles.

\begin{tabular}{llll}
\hline $\begin{array}{l}\text { Study } \\
\text { Kebeles }\end{array}$ & $\begin{array}{l}\text { Shannon-Weaver } \\
\text { diversity index(H') }\end{array}$ & $\begin{array}{l}\text { Simpson's } \\
\text { Dominance index }(\boldsymbol{\lambda})\end{array}$ & $\begin{array}{l}\text { Evenne } \\
\text { ss }(\mathbf{E})\end{array}$ \\
\hline Chichu & 3.52 & 0.0489 & 0.45 \\
Golla & 3.46 & 0.0528 & 0.42 \\
Bulla & 3.34 & 0.0568 & 0.38 \\
Shigedo & 3.37 & 0.0547 & 0.39 \\
\hline
\end{tabular}

The Shannon Weaver index shows a higher diversity of plant species in Chichu homegarden $\left(\mathrm{H}^{\prime}=3.52\right)$ as compared to the homegardens of Golla $\left(\mathrm{H}^{\prime}=3.46\right)$, Bulla $\left(\mathrm{H}^{\prime}=3.34\right)$ and Shigedo $\left(\mathrm{H}^{\prime}=3.37\right)$. The findings of this study disagree with [20] report that the plant species diversity in South Andaman was 1.38. The diversity index was least in the Bulla homegardens that means that only few species plants were more abundant. Species like Ensete ventricosum, Coffea arabica, Collocasia esculent, Ipomoea batata and Brassica carenita were more abundant than others in the Bulla homegardens but many other fruit and tree species were equally abundant in the Golla and Chichu homegardens like Mangifora indica, Musa paradisiaca, Psidium guajava, Citrus sinensis, Carica papaya, Milletia ferruginea, eucalyptus comaldulesis, Cordia africana, Croton macrostachys and Saccharum officinarum, etc. The dominance index also shows that only a few species dominated the homegardens in Bulla $(\lambda=0.056)$ as compared to Chichu $(\lambda=0.048)$, Golla $(\lambda=0.052)$ and Shigedo $(\lambda=0.054)$ homegardens. The evenness index shows that in Chichu homegardens most of the species are equally abundant $(E=$ $0.45)$ than Golla $(E=0.42)$, Bulla $(E=0.38)$ and Shigedo 


\section{( $E=0.39)$ homegardens.}

Most of the plant species recorded in homegardens was species that form multilayer canopies. Homegardens exhibit complex structure, both vertically and horizontally. The spatial arrangement of components is irregular and appears very complex with the trees, shrubs, herbs and climbers intimately mixed. As realized during observation, based on their height, vertically several relatively distinct layers are distinguished. The top layer ( $>3 \mathrm{~m}$ ) mainly consists mostly of trees such as Birbira (Milletia ferruginea), Bahirzaf (Eucalyptus comaldulesis and Eucalyptus globulas), Wanza (Cordia africana), Bisana (Croton macrostachys) and Avocado (Persea americana). Plants in this canopy use as shade for the other two layers reducing transpiration rate and hence, conserve moisture content of the soil. The middle layer $(1-3 \mathrm{~m})$ which is composed of the staple food crop, Enset (Ensete ventricosum), coffee (Coffea arabica), Mango (Mangifora indica), Banana (Musa paradisiaca), Guava (Psidium guajava), Orange (Citrus sinensis), Papaya (Carica papaya), Sugar Cane (Saccharum officinarum) and Yam (Dioscorea species) were found in the middle layer. The ground/ herb layer $(<1 \mathrm{~m})$ different vegetables, spices and medicinal plants were cultivated. The common crop plants include Godere (Collocasia esculenta), Sweet Potato (Ipomoea batata) and Brassica carenita. As a result, shade tolerant plants are adapted this layer. Similarly, [21] reported that the vertical structure of Changa homegardens is composed of 3-4 canopy layers.

All the surveyed homegardens in the present study had high species diversity index that reveal high species number in an area, besides the distribution of individuals in the systems was significant with low dominance. These features show that the homegardens of each Kebeles were more stable and matured and therefore could be self-sustaining to generate high production output under low input conditions. The high diversity observed in the homegardens must have been due to selection of the species having the potentiality to meet varied requirements of the households with utility of the specific products as the main criterion. This finding revealed that species grown in the homegarden of the study Kebeles are based on the livelihood requirements. For examples, the species that provide substantial household requirements like Ensete ventricosum, Musa paradisiaca, Persea americana, Ipomoea batata, Collocasia esculenta, Dioscorea alata and Brassica carenita were found in more than $89 \%$ of the homegardens. The dominant tree species in the home gardens include Milletia ferruginea, eucalyptus species, Cordia africana, and Croton macrostachys. Key informants and many respondents said that trees on top layer add organic matter. Particularly leaves of Milletia ferruginea would decompose at faster rate and keep soil fertility. In addition, others serve as shade and reduce transpiration rate from Ensete ventricosum leaves and other middle and bottom layer crops.

\subsubsection{Composition}

Different plant species ranging from fruits, vegetables, spices, food and cash crops, totaling about 75 plant species with ten different uses were identified in the assessed homegardens. Most of the plants species grown in the surveyed homegardens have multiple uses and therefore they not only fulfill the nutritional requirement but also in one or other case the monitory needs of the household by the sold of the products in the nearby local market. For this study, ten major plant use categories based on the farmers' interview were identified. From these plant species, $40 \%$ were food crops, $17.3 \%$ were crops used for income, $13.3 \%$ were medicinal, $17.3 \%$ were plants used as live fence, $20 \%$ were used for building and fuel, $10.6 \%$ were used for home materials, $4 \%$ were used as spices, $5.3 \%$ were stimulants, $10.6 \%$ were used as ornamentals and $20 \%$ plant species were used for shading.

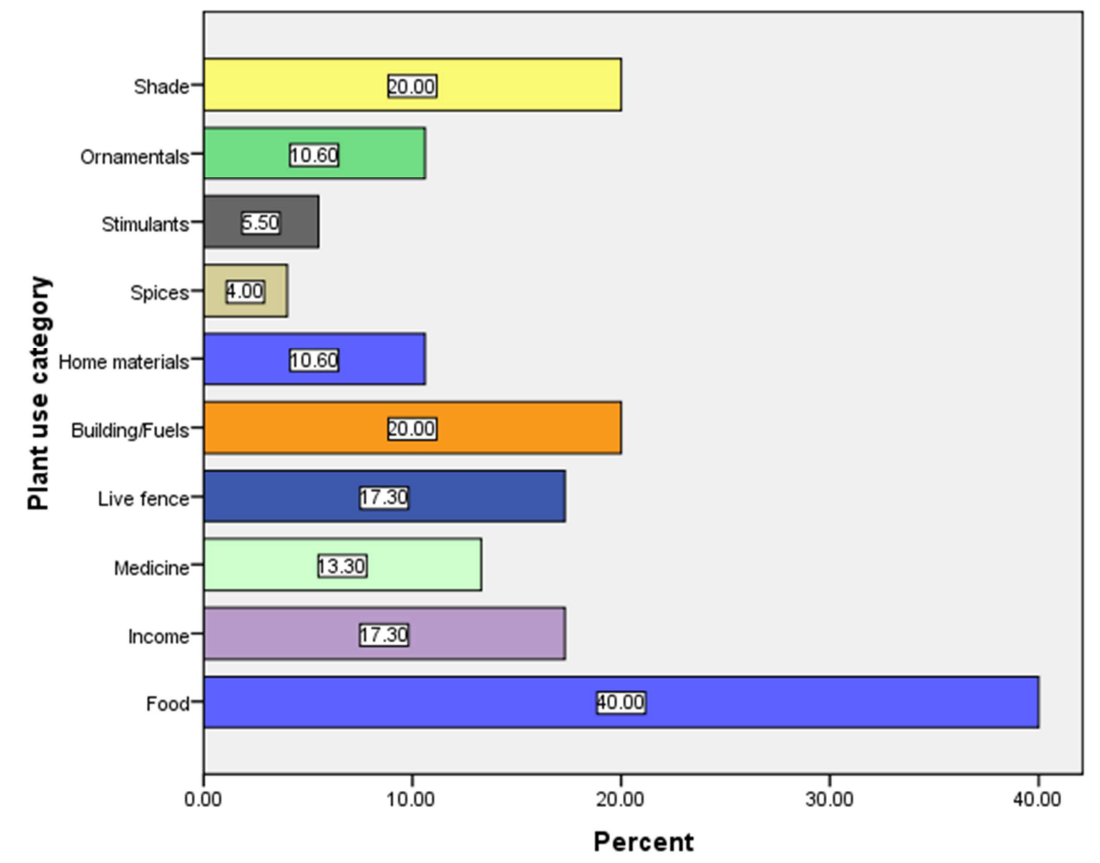

Figure 2. The use categories of the inventoried plant species in the homegarden and their percentage. 
The present study shows that the primary functions of homegardens were subsistence food production $(40 \%)$ and contributions in the family cash economy to improve their livelihood [20], reported that the most remarkable similarity among the different homegardens from diverse ecological and socio-economic background is with respect to the species composition of the herbaceous components. This is so because food production is the predominant role of most species, especially the herbaceous ones, in almost all homegardens. Tuber crops such as Taro, Cassava, Yams, Sweet potato, etc. can replace the basic staples of cereals on the one hand, and can be grown with relatively less care as understory species in partial shade and yet be expected to yield reasonable levels of carbohydrate-rich produce on the other. The fruits crops were the major constituents $(53.4 \%)$ of homegardens than any other food crops in the study area followed by vegetables (14.7\%). The root/tuber/bulb crops constitutes about $9.1 \%$ of the homegardens.

\section{Conclusion}

This study reveals that the homegardens of the study area ranges from $250 \mathrm{~m}^{2}$ (small) to $2000 \mathrm{~m}^{2}$ (large) with mean of $665.42 \mathrm{~m}^{2}$. The average plant diversity per homegaden was 21 plant species, ranging from 11 to 37 throughout the homegardens. In all the three types of homegardens, trees accounts (44\%), shrubs (14.7\%), herbs (38.6\%) and climbers $(2.7 \%)$ representing 48 families. The Shannon Weaver index shows a higher diversity of plant species in Chichu homegarden $\left(\mathrm{H}^{\prime}=3.52\right)$ as compared to the homegardens of Golla $\left(\mathrm{H}^{\prime}=3.46\right)$, Bulla $\left(\mathrm{H}^{\prime}=3.34\right)$ and Shigedo $\left(\mathrm{H}^{\prime}=3.37\right)$. The dominance index also showed that only a few species dominated the homegardens in Bulla $(\lambda$ $=0.056)$ as compared to Chichu $(\lambda=0.048)$, Golla $(\lambda=0.052)$ and Shigedo $(\lambda=0.054)$ homegardens. Besides, the evenness index showed that in Chichu homegardens most of the species are equally abundant $(E=0.45)$ than Golla $(E=0.42)$ Bulla $(E=0.38)$ and Shigedo $(E=0.39)$ homegardens. The homegardens display three vegetation layers making them typical agroforestry systems. Homegardening could result in tangible benefits for the household, including increased food for family consumption, extra income, and food reserves for emergencies and special occasions, enhanced traditional varieties and ultimately improve family food security and nutrition. Types of food crops commonly grown in homegardens in the study area include Ensete ventricosum, Coffea arabica, Colocasia esculenta, Dioscorea alata, Persea americana, Mangifora indica, Musa paradisiaca, Lycoperisicon esculentum, Zea may, Minihot esculenta, Ipomoea batata, Brassica carinata, Phaseolus lunafus etc. Access to fresh homegrown vegetables and fruits were not only ensures a more balanced diet for families with limited purchasing power, but also increases their self-reliance.

\section{Acknowledgement}

First and for most I would like to glorify and bring the greatest of all thanks to God for helping me to start and finish this research work. I would like to express my heartfelt gratitude to my advisor Dr. Daniel Fitamo for his consistent invaluable advice, comment and follow up right from the start to completion of my work. He was sincere, genuine, approachable and respectful. He continuously supported and helped by encouraging me and keeping me motivated throughout the whole research. Without his encouragement, insight, guidance, and professional expertise the completion of this research would not have been possible.

I wish to express my appreciation and sincere thanks to all my colleagues Amare Seifu, Melese Bekele and others who forwarded valuable suggestion and helped me in various ways during my study.

My thanks also go to Dilla Zuriya Woreda Agricultural Office and the local people for providing necessary data and materials. I also acknowledge all the field assistances in each Kebeles, Mr. Mariyam Ware from Shigedo, Tsegaye Rekaso from Golla, Maru Arfeso from Bulla and Eyasu Gobena from Chichu for their field assistance and interpretation of the local language Gedeoffa in to Amharic at the time of data collection. My fieldwork would not have been possible without the help of these assistances and kind staff members of the Woreda's Agricultural Office and informants who in various ways contributed to the completion of my study.

\section{References}

[1] Chris L. L. 2011. Livelihoods Grow in Gardens. Diversification booklet number 2 ( $2^{\text {nd }}$ edition). FAO, 2012.

[2] Nair PKR. 2006. Whither homegardens? Kumar B.M, Nair PKR, editors. Tropical homegardens: A time-tested example of sustainable agroforestry, pp. 355-370. Dordrecht: Springer Science.

[3] Abdoellah O. S, Hadikusumah H. Y, Takeuchi K, Satoru Okubo S and Parikesit. 2006 Commercialization of homegardens in an Indonesian village: vegetation composition and functional changes. Agroforestry Systems 68: 1-13.

[4] Vorgelegt Von. 2007. Rural Homegardens in Central Sulawesi, Indonesia: An Example for a Sustainable Agro-Ecosystem? Ph.D Dissertation, Georg-August-University. Göttingen.

[5] Helen Keller International/Asia-Pacific. 2010. Homestead food production model contributes to improved household food security, nutrition and female empowerment-Experience from scaling-up programs in Asia (Bangladesh, Cambodia, Nepal and Philippines). Nutrition Bulletin Vol. 8 Issue 1.

[6] Marsh R. 1998. Building on Traditional Gardening to improve Household Food Security. Food Nutrition and Agriculture No. 20, Food and Agriculture Organization.

[7] Uddin M. B and Mukul S. A. 2004. Improving Forest Dependent Livelihoods through NTFPs and Home Gardens: A Case Study from Satchari National Park. 
[8] Bashir Jama, Eyasu Elias and Kebadire Mogotsi. 2006. Role of agroforestry in improving food security and natural resource management in the drylands: a regional overview. Journal of the dry lands 1(2): 206-211.

[9] Tadesse Kippie. 2002. Five Thousand Years of Sustainablity? A Case study on Gedeo Land Use (Southern Ethiopia). Treemail publishers, Heelsum, Netherland.

[10] Tesfaye Abebe. 2005. Diversity in homegarden agroforestry systems in Southern Ethiopia. $\mathrm{PhD}$ thesis Wageningen University, Wageningen.

[11] Taye Kufa and J. Burkhardt. Physiological Growth Response in Seedlings of Arabica Coffee Genotypes under Contrasting Nursery Microenvironments. Plant. Vol. 3, No. 5, 2015, pp. 47-56.

[12] Midmore D. J, Niñez V, and Venkataraman R. 1991. Household gardening Projects in Asia: experience and future directions. Asian Vegetable Research and Development Center, Technical Bulletin No. 19, 28 p.

[13] Bogale Teferi. 2007. The Map of Study Area.

[14] SPSS Inc. 2007. SPSS Version 16. SPSS Incl., Chicago, Illinois, USA.

[15] Shannon, C. E., and Wiener, W. 1949. The mathematical theory of Communication. Unversity of Illions Press. Urbana III.
[16] Olajide-Taiwo F. B, Adeoye I. B, Adebisi-Adelani O, Odeleye O. M. O, Fabiyi A. O and Olajide-Taiwo L. O. 2010. Assessment of the Benefits and Constraints of Homegardening in the Neighborhood of the National Horticultural Research Institute, Ibadan, Oyo State. American-Eurasian J. Agric. and Environ. Sci., 7 (4): 478-483.

[17] Gautam, R, BR Sthapit and PK Shrestha (eds.) 2006. Homegardens in Nepal: Proceeding of a workshop on "Enhancing the contribution of homegarden to on-farm management of plant genetic resources and to improve the livelihoods of Nepalese farmers: Lessons learned and policy implications", 6-7 August 2004, Pokhara, Nepal. LI-BIRD, Biodiversity International and SDC.

[18] Das .T and Das A. K. 2005. Inventorying plant biodiversity in homegardens: A case study in Barak Valley, Assam, North East India. Current Science, Vol. 89, No. 1, 10 July 2005.

[19] Chaminda Egodawatta and, Rasika Warnasooriya. 2014 Diversity of tree flora in homegardens in urban proximityof Anuradhapura city, Sri Lanka. Agriculture, Forestry and Fisheries. Vol. 3, No. 1, 2014, pp. 34-39.

[20] Pandey C. B, Kanak Lata, Venkatesh. A \& Medhi R. P. 2006. Diversity and species structure of home gardens in South Andaman. Tropical Ecology 47(2): 251-258.

[21] Fernandes, E. C. M. and Nair, P. K. R. 1986. An evaluation of the structure and function of tropical home-gardens. ICRAF. Working paper. No. 38. Nairobi, Kenya. 